\title{
Using network-based theory to develop a curriculum for citizenship education in higher institutions
}

\begin{abstract}
The civic development of higher education students is currently recognized as a critical issue in education research. Numerous studies have investigated the development of civic skills; however, to date, no study has provided a comprehensive overview of the benefits and functions of horizontal networks among students as the main tool in their civic development in the form of citizenship education programs. This paper presents an approach based on network theory to create a horizontal network model of citizenship education that dynamically supports civic development in higher education. The theory emphasizes four main purposes of horizontal networks towards civic developmentð facilitating change, transferring civic knowledge, reinforcing civic norms, and enhancing civic learningð that may allow students of higher education to serve as vital building blocks for the development of a lively civil society. This study provides an account of the cumulative knowledge regarding how these horizontal networks assist students to perform within the main components of an education system. It is suggested that higher education authorities need to focus on these networks, and redesign programs to facilitate their creation among students.
\end{abstract}

Keyword: Citizenship education programs; Civic development; Higher education; Social networks; Horizontal networks; Curriculum; Learning; Assessment 